\title{
An Introduction to Special Issue: Sustainability and Ethical Consumption
}

We are pleased to present this special issue of Management Decision, the aim of which is to advance an in-depth understanding of the area of sustainability and ethical consumption and to proffer new possibilities for future research. This topic has been drawing significant attention, more so in recent decades, as was evident in the large number of manuscripts that were submitted to this issue. We are very delighted to introduce the ten articles in this special issue. Each of these papers furthers understanding of sustainability and ethical consumption and, together, they provide novel directions for future studies.

We first explicate the main concepts that form the basis of this special issue, sustainability and ethical consumption. We then provide an overview of the articles in this issue, highlighting various topics pertaining to this research area.

\section{Sustainability and Ethical Consumption}

The current expansion of contemporary capitalism manifests itself in the harm being occasioned to the environment and the promulgation of social and economic exploitation of the individual and societally. Increasingly, the need to take ecological and human social aspects into consideration when pursuing sustainable development objectives, is impinging on the awareness of more businesses (Slawinski and Bansal, 2015).

The World Commission on Environment and Development (WCED) has defined sustainable development as one "that meets the needs of the present without compromising the ability of future generations to meet their own needs" (WCED, 1987, pp. 43). This fundamental definition of sustainable development offers a descriptor which clearly is indicative of the perceptions of cause and effect, signifying that today's needs should not be fulfilled at the sacrifice of tomorrow's generations. The sustainability debate is poly faceted with multiple 
voices whose dynamic is a function of psychological acculturation and political expediency resulting in an increasing number of environmental regulations. This, despite recognition and awareness of sustainability issues at national and local levels and the existence of multiple legislative attempts at regulation. Self-regulation in industry has been attempted, although, not always with complete success. Sustainability is also becoming a fundamental aspect of strategic decision making in contemporary businesses, guiding management in assessment risks which impinge upon the gamut of their business practices (Gupta et al., 2014).

The emphasis on balancing financial, societal and environmental aspects of running a business has evoked a stream of relevant research which studies the relationships between industry and society. Over the past three decades research on sustainability has seen a growing trend in areas such as: sustainable innovation, supply chain management, marketing, information systems and accounting and finance (Ming-hui and Rust, 2011), whilst Corporate Social Responsibility effectively dominates much of business studies (Lee et al., 2012).

At the same time, there has been an increase of consumer awareness of the impact of ethical behavior in the context of human welfare and environmental issues, and this has seen an exponential growth in research into ethical consumerism. As a result, ethical consumption is no longer considered as a niche (Carrington et al., 2014; Caruana et al., 2016). Consumers have become aware that they can effect change by changing the products which they buy, and are changing their behavior accordingly.

From a business management and consumer behavior viewpoints, we acknowledge the significant role that sustainability and ethical consumption play in todays' field of management theory and practice. This special issue covers many topics within sustainability and ethical consumption, which sometimes share commonalities and are yet distinct.

\section{Papers in this Special Issue:}


We called for empirical and conceptual submissions that offer valuable contributions which have significant theoretical and managerial implications and review pertinent issues in sustainability and ethical consumption. The articles in this issue deal with a range of topics from philanthropic engagement, ethical investment in corporations, collaborative framework for balancing stakeholder power and social responsibilities to responsible consumer behavior, fair trade movement, mapping the sharing economy for sustainability, ethical product attributes, green purchase intention, and the role of information to ethical consumers. The studies in this issue employ different methodologies (quantitative, qualitative and conceptual) and study different stakeholders (consumers, organizations).

The first three papers focus on the organizational perspective on sustainability. The opening paper 'The effect of firm strategic orientation on corporate philanthropic engagement' (Abebe and Cha, 2018) focuses on the key role of corporate strategic orientations as drivers of organization's philanthropic engagement. In particular, the authors examine relationship of two broad demonstrate corporate strategic orientation: domain offence and domain abandonment strategies with the level of philanthropic engagement exhibited by the organizations. For this purpose, data from 122 publicly traded US organizations from 2008 to 2013 were examined to determine the relationship between corporate strategic policies and philanthropic engagement. The authors found that there was a positive relationship between domain offence strategies and philanthropy, whilst the contrary was reported for domain abandonment strategies. As a result, the findings of this study propose an important link between domain offence strategies and corporate philanthropy. The second study titled 'Perfectionist decision-making style and ethical investment willingness: a two-factor causal mediation model' by Lin et al. (2018) aims to examine the ethical investment willingness decision-making process of the investors in a CSR context. They found that perfectionist decision-making style is a driver for perceived moral intensity, 
substitutability of financial returns, and ethical investment willingness. Further, perceived moral intensity and substitutability of financial returns were found to be positively related to ethical investment willingness. Also, the authors found support for a two-factor causal mediation model, as perceived moral intensity is positively related to substitutability of financial returns. The third study titled 'For the balance of stakeholders' power and responsibility. A collaborative framework for implementing social responsibility issues in construction projects' by Lin et al. (2018) focus on developing and designing a collaborative framework for balancing stakeholder power and social responsibilities in construction projects. Adopting a multi-phase case study approach in a real estate project in China, the authors substantiated the framework and found that stakeholder engagement is enhanced by implementing the framework, also leading to better communication and trust, and increased collaboration through a collective form of responsibility.

From a collaborative sustainable development view point, in the fourth paper titled 'Mapping the sharing economy for sustainability research', Plewnia and Guenther (2018) develop a holistic framework of sharing economy including various business models and activities. In this conceptual paper, they propose four main dimensions characterising sharing economy, namely, shared good or service, market structure, market orientation, and industry sector.

The remaining papers deal with a range of topics within ethical consumption. The fifth paper titled "Selecting decision-relevant ethical product attributes for grocery shopping" by Hasanzade et al. (2018) aims at understanding consumer preferences for the provision of relevant product production information (labour exploitation, animal welfare and environment) which could address underlying uncertainties and add impetus to address concerns about ecological matters. The authors determine three consumer segments, ethically motivated, price oriented and price-quality oriented consumers. They also argue that 
information about animal welfare is most important to the consumers in making decisions followed by information about human and labour rights and environmental protection.

The objective of the sixth study titled 'Sustainable consumption: Insights from the protection motivation (PMT), deontic justice (DJT) and construal level (CLT) theories' by Ibrahim and Al-Ajlouni (2018) is the examination of the role of Deontic Justice, Protection Motivation and Construal Level theories to understand green motivations and intentions. The authors, through an experimental survey, involving 471 participants, propose and test the influence of threat appraisal, coping appraisal, and deontic justice dimensions on green purchase intention. The authors also study construal variable as a moderator in the relationship between these variables and green purchase intention.

In the seventh paper titled 'Fair trade and consumer social responsibility exploring consumer citizenship as a driver of social and environmental change' Anderson (2018) explores the historical perspective of fair trade consumers. The influence of the ethical consumer as a motivator for change is examined in the context of Fair Trade, which has now expanded beyond the original north-south divide and now encompasses such emergent economies as India, South Africa and Brazil. Hence, the position of the consumer as an agent for change is of significance to this study and the grouping of consumers into four subtypes is proposed for convenience. These subtypes are considered to be consumers whose concerns are moral action and simple living, living in the world as citizen consumers, solidarity with the marginalized producers, and demand choice. The paper also examines the potential for and impact of globalizing the citizen-consumer and the effects on Fair Trade consumption.

The eight paper "Looking for info? Understanding ethical consumer information management using a diary approach" by Papaoikonomou et al. (2018) investigates the role of information in relation to ethical consumption. The authors examine the information search and use of this information by ethical consumers, unpacking the related issues and examining how 
consumers address them. By employing a longitudinal qualitative design over 11 weeks, with interviews and diary records, they explained the importance of information search, use and timing of information. They found that consumers spend time and effort in information search and processing regarding a purchase decision. The authors also identify key issues in information management owing to which consumers often shift from maximizers to optimisers.

The ninth paper 'Moral avoidance for people and planet: Anti-consumption drivers' by Sudbury-Riley and Kohlbacher (2018) examine the reasons for moral avoidance as a form of anti-consumption among older consumers and propose that concerns for the planet and human exploitation are the two main causes of moral avoidance. Using a quantitative survey of 457 UK consumers, results confirm existence of two forms of anti-consumption, ecological anti-consumption, related to the exploitation of the planet and social anticonsumption, owing to exploitation of humans. The authors also found that ecological concerns and perceived consumer effectiveness are key predictors to both forms, while ethical ideology also influences anti-consumption.

The tenth article, Ethical consumption and consumers' decision making: the role of moral intuition by Zollo et al. (2018) examines the predictors of moral reasoning and cognitive processes which impinge upon adoption of an ethical posture by the consumer by employing the Theory of Planned Behaviour and the socio-intuitionist model. They also propose holistic, inferential, and affective dimensions of intuition as the antecedents of environmental concerns which then impact ethical consumption. It is argued that the only significant antecedent of this is inferential intuition. This, in turn, has born considerable influence on the dimensions of eco-friendly consumer behavior.

Overall, the articles included in this special issues provide meaningful insights in wide ranging topics in the broader literature of sustainability and ethical consumption. The papers 
in this special issue help us understand the diverse and complex issues in this field of study. We hope that this issue will generate a momentum for new research ideas in management studies pertaining to sustainability and ethical consumption.

\section{Acknowledgments}

We would like to express gratitude to all the authors who submitted their manuscripts to this special issue. We also appreciate the efforts of the volunteer reviewers who provided their valuable comments on the manuscripts without whom this special issue would not have been possible. We would also like to thank Andy Adcroft and the editorial office for providing continued support.

\section{References:}

Caruana, R., Carrington, M. J., \& Chatzidakis, A. (2016). "Beyond the Attitude-Behaviour Gap: Novel Perspectives in Consumer Ethics": Introduction to the Thematic Symposium. Journal of Business Ethics, Vol. 136. No. 2, pp. 215-218.

Carrington, M. J., Neville, B. A., \& Whitwell, G. J. (2014). Lost in translation: Exploring the ethical consumer intention-behavior gap. Journal of Business Research, Vol. 67. No. 1, pp. $2759-2767$.

Gupta, S., Rudd, J. and Lee, N., 2014. Business sustainability through successful integration of marketing and operations. Industrial Marketing Management, Vol. 43. No. 1, pp.3-5.

Huang, M.H. and Rust, R.T., 2011. Sustainability and consumption. Journal of the Academy of Marketing Science, Vol. 39. No. 1, pp.40-54.

Lee, E. M., Park, S. Y., Rapert, M. I., \& Newman, C. L. (2012). Does perceived consumer fit matter in corporate social responsibility issues?. Journal of Business Research, Vol. 65. No. 11, pp. $1558-1564$. 
Slawinski, N. and Bansal, P., 2015. Short on time: Intertemporal tensions in business sustainability. Organization Science, Vol. 26. No. 2, pp.531-549.

WCED. 1987. Our Common Future. Oxford University Press: Oxford. 